\title{
Synthesis of Polyethylenamine Cellulose and Its Absorbing Ability to Chromium (VI)
}

\author{
Rui Liu ${ }^{1}$, Jiao-Qiang Zhang ${ }^{1,} \mathrm{a}^{*}, \mathrm{Na} \mathrm{Yi}^{1}$, Tie-Zheng $\mathrm{Ji}^{1}$, Ying Zhang ${ }^{1}$ \\ ${ }^{1}$ Key Laboratory of Applied Physics and Chemistry in Space, Ministry of Education, \\ Applied Chemistry Department, School of Science, Northwestern Polytechnical University, \\ Xi'an, Shanxi, 710072, P.R China \\ azhangjq@nwpu.edu.cn
}

\section{Keywords: Polyethylenamine Cellulose, Adsorbent, $\mathrm{Cr}(\mathrm{VI})$, Adsorption Dynamics}

\begin{abstract}
The study was conducted regarding the adsorption effect of $\mathrm{Cr}(\mathrm{VI})$ on polyethylenamine cellulose, the affecting factors on the adsorption of $\mathrm{Cr}(\mathrm{VI})$, such as $\mathrm{pH}$ value, adsorption time, polyethylenamine cellulose dose and initial concentration of $\mathrm{Cr}(\mathrm{VI})$ were investigated. The results showed that adsorption efficiencies of $\mathrm{Cr}(\mathrm{VI})$ is more than $90 \%$, the suitable conditions for the

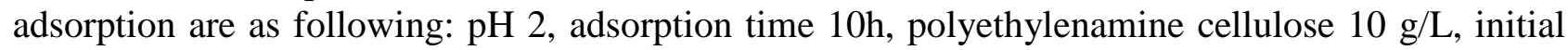
concentration of $\mathrm{Cr}(\mathrm{VI}) 10 \mathrm{mg} / \mathrm{L}$. The adsorption isotherms could be well fitted by both Langmuir and Freundlich equation. The law of dynamics for the adsorption can be simulated by pseudo-first order and pseudo-second order kinetics models.
\end{abstract}

\section{Introduction}

Electroplating, tanning, mining, and dye industries have produced large amounts of mercury, lead, cadmium, arsenic and chromium in waste water, which are detrimental to human health and ecological environment. Currently, there are several techniques to treat heavy metals in wastewater [1], heavy metal ions can be removed by oxidation-reduction [2], chemical precipitation [3], ion exchange [4], and membrane separation [5] methods. Especially adsorption and ion exchange methods, which are the common methods to treat heavy metal, have the advantages of high efficiency, easy to operate and lower energy consumption. Activated carbon and ion exchange resins are common adsorbents and ion exchange agent, but they are expensive and have regeneration difficulties. In recent years, researchers have been working to find low-cost adsorption material, and then the cellulose has its own unique advantages. Cellulose adsorption material is taken from the agricultural and sideline products, and is cheap, so the material has bright prospects.

In this paper, polyethylenamine cellulose is employed as the adsorbent to remove $\mathrm{Cr}(\mathrm{VI})$ in solution, the factors, which are interrelated with $\mathrm{Cr}(\mathrm{VI})$ removing, the $\mathrm{pH}$ value, the adsorption time, the amount of polyethylenamine cellulose and the initial concentration of $\mathrm{Cr}(\mathrm{VI})$, were investigated, then the suitable conditions for the adsorption was optimized.

\section{Materials and Experimental Method}

Reagents and Instruments. All reagents and solvents were of analytical grade. The measurements were carried out with a 722 spectrophotometer (Shanghai, China) using 1.00-cm quartz cells. The $\mathrm{pH}$ measurements were performed with a $\mathrm{pH}$-meter ( $\mathrm{pHS}-3 \mathrm{C} \mathrm{pH}$ meter) equipped with a glass electrode with the $\mathrm{Ag} / \mathrm{AgCl}$ reference electrode.

Experimental Methods. $3 \mathrm{~g}$ straw cellulose was immersed in a solution of $30 \mathrm{~g}$ sodium hydroxide in $70 \mathrm{~mL}$ deionized water. The mixture was then stirred at room temperature for $1 \mathrm{~h}$ and the cellulose was filtered. Then, the cellulose was reacted with $8 \%$ sodium hydroxide solution and $15 \mathrm{~mL}$ epichlorohydrin at $45^{\circ}$ for $15 \mathrm{~h}$, which was filtered, washed firstly with deionized water, then with acetone, and dried at $70^{\circ} \mathrm{C}$. Thus, the epoxidized cellulose was obtained. After this, $100 \mathrm{~mL}$ deionized water, $1 \mathrm{~g}$ sodium carbonate, epoxidized cellulose and diethylenetriamine in a mass ratio 
(1:1) were added into flask. The mixture was reacted at $50^{\circ} \mathrm{C}$ for $8 \mathrm{~h}$. Next, the product was filtered, washed to neutral, dried in an oven at $70^{\circ} \mathrm{C}$ and used as an adsorbent. Its structure was characterized by scanning electronic (SEM) and Fourier transform infrared spectrum (FTIR) [6].

The absorption experiments of $\mathrm{Cr}(\mathrm{VI})$ ions on polyethylenamine cellulose were performed from aqueous solution of bichromate of potash at room temperature for different $\mathrm{pH}$ value and periods of time. Also, the effects of polyethylenamine cellulose dosage and the initial concentrations of $\mathrm{Cr}(\mathrm{VI})$ ions in solution were studied. All the experiments were carried out in batch process. Polyethylenamine cellulose was shaken in $50 \mathrm{~mL} \mathrm{Cr}(\mathrm{VI})$ ions solution in $100 \mathrm{~mL}$ beaker. The residual concentration of $\mathrm{Cr}(\mathrm{VI})$ is calculated with standard working curve, which is determined by diphenylcarbohydrazide spectrophotometric method [7]. The removal rate and the adsorption capacity of $\mathrm{Cr}(\mathrm{VI})$ by polyethylenamine cellulose were calculated by the following equation:

$$
\begin{aligned}
& \eta=\frac{C_{0}-C_{e}}{C_{0}} \times 100 \% \\
& q_{e}=\frac{\left(C_{0}-C_{e}\right) \cdot V}{m}
\end{aligned}
$$

where, $\eta(\%)$ is removal rate of $\mathrm{Cr}(\mathrm{VI}), C_{0}(\mathrm{mg} / \mathrm{L})$ and $C_{e}(\mathrm{mg} / \mathrm{L})$ are original and equilibrium concentration of $\mathrm{Cr}(\mathrm{VI})$ in solution, respectively, $q_{e}(\mathrm{mg} / \mathrm{g})$ is adsorption capacity for adsorbent, $V(\mathrm{~L})$ is the volume of processing solution, and $\mathrm{m}(\mathrm{g})$ is the adsorbent mass.

\section{Results and Discussions}

The Effect of Solution pH. When solution $\mathrm{pH}$ value is $2, \eta$ is $91.1 \%$; when solution $\mathrm{pH}<2, \eta$ declines, as the acid concentration increases, the $\mathrm{H}_{2} \mathrm{Cr}_{2} \mathrm{O}_{7}$ concentration also increases, which affects exchange interaction between $-\mathrm{NH}_{3}{ }^{+}$and $\mathrm{HCr}_{2} \mathrm{O}_{7}{ }^{-}$or $\mathrm{Cr}_{2} \mathrm{O}_{7}{ }^{2-}$; when solution $\mathrm{pH}$ value is 13 , $\eta$ is only $18.1 \%$, the figure shows, when solution $\mathrm{pH}$ value between 2 and $3, \eta$ is more than $85 \%$. Therefore, in these experiments the initial solution $\mathrm{pH}$ value will be adjusted to 2 .

The Effect of Adsorption Time. The removal rate approximately took place in the first $9 \mathrm{~h}$ and reached equilibrium after about $10 \mathrm{~h}$, and then reached $91.1 \%$. Next the adsorption rate gradually slow down, removal rate remained stable. In subsequent experiments, the adsorption time was maintained $10 \mathrm{~h}$.

The Effect of Polyethylenamine Cellulose Dosage. When increasing the polyethylenamine cellulose dosage, the removal rate of $\mathrm{Cr}(\mathrm{VI})$ is improved. When the amount of polyethylenamine cellulose is $10 \mathrm{~g} / \mathrm{L}$, the removal rate is $91.1 \%$. Continue to increase the dosage, the curve approached to a flat, the increasing degree of removal rate of $\mathrm{Cr}(\mathrm{VI})$ improved in decreasing trend, which is fitted regularity of absorption. The amount of polyethylenamine cellulose dosage is selected as $10 \mathrm{~g} / \mathrm{L}$ in the succedent experiments.

The Effect of Initial Concentration of $\mathrm{Cr}(\mathrm{VI})$ in Solution. With the initial concentration of $\mathrm{Cr}(\mathrm{VI})$ increasing, the removal rate is decreasing. When the initial concentration of $\mathrm{Cr}(\mathrm{VI})$ is less than 10 $\mathrm{mg} / \mathrm{L}$, the removal rate is up to $90 \%$; when the initial concentration is $50 \mathrm{mg} / \mathrm{L}$, the removal rate was $64.39 \%$. So the polyethylenamine cellulose is suitable for treating low concentration of $\mathrm{Cr}(\mathrm{VI})$ wastewater.

Adsorption Isotherm Investigation. Knowledge of adsorption isotherm is required for better understanding features of the adsorbent/adsorbate system like their affinity or sorption capacity. The polyethylenamine cellulose dosage is fixed to $10 \mathrm{~g} / \mathrm{L}$, and the initial concentrations of $\mathrm{Cr}(\mathrm{VI})$ are changed under the conditions of $\mathrm{pH} 2$, the solution is stirred $10 \mathrm{~h}$ to make adsorption equilibrium, the residual concentrations of $\mathrm{Cr}(\mathrm{VI})$ in solution were determined, according which the adsorption capacities of $\mathrm{Cr}(\mathrm{VI})$ by polyethylenamine cellulose were calculated, the adsorption isotherm of $\mathrm{Cr}(\mathrm{VI})$ on polyethylenamine cellulose is depicted in Fig. 1. The adsorption isotherm proceedings are characterized by Langmuir and Freundlich equations [8], the results are shown in Fig. 2 and Fig. 3. 
Langmuir adsorption isotherm equation:

$C_{e} / q_{e}=C_{e} / q_{m}+1 /\left(k_{1} \bullet q_{m}\right)$

Freundlich adsorption isotherm equation:

$\lg q_{e}=\lg k_{f}+1 / n \lg C_{e}$

In the Eq. (3) and (4), $q_{e}(\mathrm{mg} / \mathrm{g})$ is adsorption equilibrium capacity, $q_{m}(\mathrm{mg} / \mathrm{g})$ is saturated adsorption capacity, $k_{1}$ is adsorption equilibrium constant, $C_{e}(\mathrm{mg} / \mathrm{L})$ is the adsorption equilibrium concentration, $k_{f}$ is Freundlich adsorption coefficient, $\mathrm{n}$ is the constant.

The parameters are shown in Table 1, the correlation coefficient of matched curve shows, the Langmuir and the Freundlich isotherm equations are well fitted results. The maximum adsorption capacity of $\mathrm{Cr}(\mathrm{VI})$ on polyethylenamine cellulose is $3.64 \mathrm{mg} / \mathrm{g}$ from the Langmuir equation. The Freundlich adsorption constant $k_{f}$ is often used to indicate the relative quantity of absorbability, $1 / \mathrm{n}$ is used to represent the adsorption degree of difficulty.

Table 1. Langmuir and Freundlich adsorption isotherm constants.

\begin{tabular}{lccccc}
\hline & \multicolumn{3}{c}{ Langmuir isotherm } & \multicolumn{3}{c}{ Freundlich isotherm } \\
\hline$q_{m}(\mathrm{mg} / \mathrm{g})$ & $k_{1}$ & $R^{2}$ & $1 / n$ & $k_{f}$ & $R^{2}$ \\
3.64 & 0.2016 & 0.8246 & 0.39 & 0.88 & 0.9431 \\
\hline
\end{tabular}

*Symbols are defined in the text

The Adsorption Kinetics Model. The rate of adsorption is highly important in the design and evaluation of adsorbents in removing $\mathrm{Cr}(\mathrm{VI})$ from the solution. There are a variety of adsorption kinetic models, pseudo-first and pseudo-second order models are employed to correlate the kinetic data. The pseudo-first-order kinetic adsorption model was suggested for the sorption of solid/liquid systems [9]. The pseudo-second order model is based on the assumption that the rate limiting step may be chemisorption which involves valence forces by sharing or electron exchange between the adsorbent and the adsorbate [10].

The integral of pseudo-first and pseudo-second order kinetic model can be expressed as given below [11, 12]:

$$
\begin{aligned}
& \ln \left(q_{e}-q_{t}\right)=\ln q_{e}-k t \\
& \frac{t}{q_{t}}=\frac{1}{k_{1} q_{e}^{2}}+\frac{t}{q_{e}}
\end{aligned}
$$

where, $q_{e}$ and $q_{t}(\mathrm{mg} / \mathrm{g})$ are the adsorption loading of $\mathrm{Cr}(\mathrm{VI})$ at equilibrium and at time $\mathrm{t}(\mathrm{min})$, respectively, $k[\mathrm{~g} /(\mathrm{mg} \cdot \mathrm{min})]$ and $k_{1}[\mathrm{~g} /(\mathrm{mg} \cdot \mathrm{min})]$ are pseudo-first and pseudo-second rate constants of adsorption, respectively.

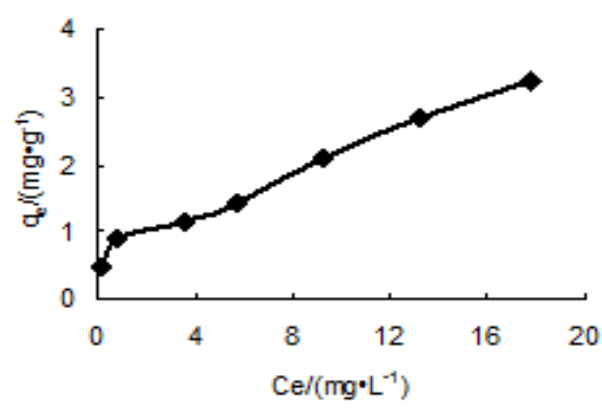

Fig. 1 Adsorption isotherm of $\mathrm{Cr}(\mathrm{VI})$ on polyethylenamine cellulose. 


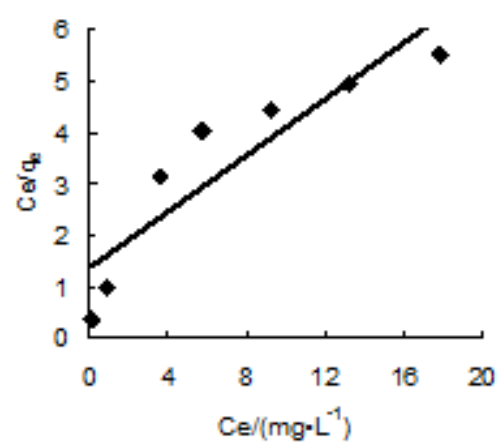

Fig. 2 The Langmuir adsorption isotherm of $\mathrm{Cr}(\mathrm{VI})$ on polyethylenamine cellulose.

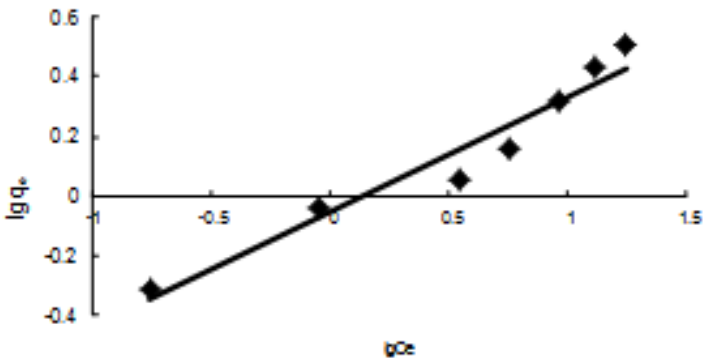

Fig. 3 The Freundlich adsorption isotherm of $\mathrm{Cr}(\mathrm{VI})$ on polyethylenamine cellulose.

A plot of $\ln \left(\mathrm{q}_{\mathrm{e}}-\mathrm{q}_{\mathrm{t}}\right)$ versus $\mathrm{t}$ is provide in Fig. 4, from which $\mathrm{k}$ and $\mathrm{q}_{\mathrm{e}}$ were calculated as 0.003 $\mathrm{g} /(\mathrm{mg} \cdot \mathrm{min})$ and $0.9105 \mathrm{mg} / \mathrm{g}$, respectively. Plotting $\mathrm{t} / \mathrm{q}_{\mathrm{t}}$ against $\mathrm{t}$ (Fig. 5), a straight line is obtained and the rate constant $\mathrm{k}_{2}$ as well as $\mathrm{q}_{\mathrm{e}}$ can be calculated as $0.0186 \mathrm{~g} /(\mathrm{mg} \cdot \mathrm{min})$ and $0.8768 \mathrm{mg} / \mathrm{g}$, respectively. The linear coefficients (r) were 0.833 and 0.9303 for pseudo-first and pseudo-second order kinetic mode, respectively.

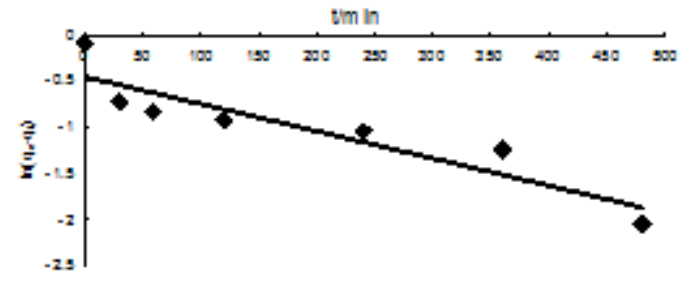

Fig. 4 Pseudo-first order plot of $\mathrm{Cr}(\mathrm{VI})$ adsorption onto polyethylenamine cellulose.

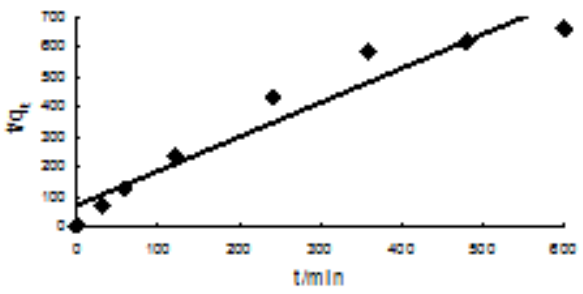

Fig. 5 Pseudo-second order plot of Cr(VI) adsorption onto poly-ethylenamine cellulose.

\section{Conclusions}

The results showed that the adsorption efficiencies of $\mathrm{Cr}(\mathrm{VI})$ on polyethylenamine cellulose is more than $90 \%$. The factors such as $\mathrm{pH}$ value, adsorption time, amount of polyethylenamine cellulose and initial concentration of $\mathrm{Cr}(\mathrm{VI})$ all affect the $\mathrm{Cr}(\mathrm{VI})$ removing rate. The suitable conditions for $\mathrm{Cr}(\mathrm{VI})$ adsorption are as following: $\mathrm{pH} 2$, adsorption time $10 \mathrm{~h}$, polyethylenamine cellulose dosage $10 \mathrm{~g} / \mathrm{L}$, initial concentration of $\mathrm{Cr}(\mathrm{VI}) 10 \mathrm{mg} / \mathrm{L}$. 
The adsorption isotherm of $\mathrm{Cr}(\mathrm{VI})$ on polyethylenamine cellulose matches the Langmuir and the Freundlich adsorption isotherm, the correlation coefficients were 0.8246 and 0.9431 , respectively, the correlation coefficient of the Freundlich adsorption is greater than one of the Langmuir, therefore, the Freundlich isotherm model is more suitable for describing the adsorption process of $\mathrm{Cr}(\mathrm{VI})$ on polyethylenamine cellulose than ones of the Freundlich.

The adsorption kinetics of $\mathrm{Cr}(\mathrm{VI})$ on polyethylenamine cellulose are fitted to the pseudo first and second order kinetic equation, and the correlation coefficients were 0.833 and 0.9303 , respectively. So, the adsorption kinetic of $\mathrm{Cr}(\mathrm{VI})$ on polyethylenamine cellulose is more fitted to the second order kinetic equation than that of the first ones.

\section{Reference}

[1] Q. W. Liu, Treatment methods of heavy metal ions in wastewater, Tianjin Chem. Industry (4) (1995) 16-18.

[2] W. Q. Luo, C. H. Liu, The determination and recovery of electroplating chromium in wastewater, J. Ankang Teachers Coll. 15 (2003) 74-75.

[3] X. Huang, T. Li, K. Tang, Y. L. Sun, et al, Study on recycling of nickel in nickel wastewater by chemical precipitation, Chem. Eng. (10) (2008) 37-39.

[4] Y. Sag, T. Kutsal, Determination of the biosorption heats of heavy metal ions on zoogloea ramigera and rhizopus arrhizus, Biochem. Eng. J. 6(2) (2000) 145-151.

[5] W. G. Shu, G. Liang, Separation of $\mathrm{Cu}^{2+}$ by emulsion liquid membrane, Membr. Sci. Technol. 18(1) (1998) 14-17.

[6] Y. Zhang, J. Q. Zhang, X. M. Kang, T. Z. Ji, K. C. Kou, The preparation of cellulose polyethylenamine adsorbent, Dev. App. Mater. 26(2) (2011) 56-59.

[7] GB/T 7467-87, Water quality-determination of chromium (VI) 1. 5 Diphenylcarbahydrazide spectrophotometric method, National Standard of The People's Republic of China. National Standard of the People's Republic of China.

[8] Z. Aksu, Application of biosorption for the removal of organic pollutants: a review, Process Biochem. 40 (3-4) (2005) 997-1026.

[9] Y. J. Yao, B. He, F. F. Xu, X. F. Chen, Equilibrium and kinetic studies of methyl orange adsorption on multiwalled carbon nanotubes, Chem. Eng. J. 170( 2011) 82-89.

[10] K. Y. Foo, B. H. Hameed, Textural porosity, surface chemistry and adsorptive properties of durian shell derived activated carbon prepared by microwave assisted $\mathrm{NaOH}$ activation, Chem. Eng. J. 187(2012) 53-62.

[11] M. S. Chiou, H. Y. Li, Equilibrium and kinetic modeling of adsorption of reactive dye on cross-linked chitosan beads, J. Hazard. Mater. 93(2) (2002) 233-248.

[12] M. Doğan, M. Alkan, Adsorption kinetic of methyl violet onto perlite, Chemosphere 50(4) (2003) 517-528. 